\title{
Physical model of the development of external signs of barotrauma in Pacific rockfish
}

\author{
Robert W. Hannah ${ }^{1, *}$, Polly S. Rankin ${ }^{1}$, Alexandra N. Penny ${ }^{2}$, Steven J. Parker ${ }^{3}$ \\ ${ }^{1}$ Oregon Department of Fish and Wildlife, Hatfield Marine Science Center, 2040 SE Marine Science Drive, Newport, \\ Oregon 97365, USA \\ ${ }^{2}$ Brown University, Providence, Rhode Island 02912, USA \\ ${ }^{3}$ National Institute of Water and Atmospheric Research, Private Bag 14901, Wellington, New Zealand
}

\begin{abstract}
Four species of Sebastes (Pacific rockfish) showed evidence of a wide array of internal injuries from capture-induced barotrauma, including liver and swimbladder damage, organ displacement related to esophageal eversion, and hemorrhage in the pericardium and abdominal cavity. However, clear evidence of swimbladder rupture was not observed in all fish with external signs of barotrauma. Injection of air through the body wall into the swimbladders of rockfish carcasses generated all of the common external signs of barotrauma documented in wild-captured fish, suggesting that the physical effects of swimbladder gas expansion can create these gross external signs without embolism from dissolved blood gases. Dissections of injected black rockfish $S$. melanops carcasses showed that, typically, injected air escaped the swimbladder without obvious rupture, moving in an anterio-dorsal direction, generating bulges and air bubbles that were externally visible through the branchiostegal membrane. Injected air also collected dorsally to the esophagus, posterior to the pharyngeal teeth, causing the esophagus to roll outwards into the buccal cavity (esophageal eversion). Injected air also frequently traveled further forward, collecting medially to the eyeball, leading to exophthalmia, and then moved distally along the fascia, invading the corneal stroma from the edges, resulting in corneal emphysemas. Air injected into the swimbladders of quillback rockfish $S$. maliger carcasses generated similar eye effects, but also escaped through ruptures in the branchiostegal membrane and did not generate esophageal eversion, which is also infrequent in wild-caught specimens. These results demonstrate that the major external signs of barotrauma in Pacific rockfish can develop as result of escaping swimbladder gases following an internal 'path of least resistance'.
\end{abstract}

KEY WORDS: Discard mortality $\cdot$ Sebastes $\cdot$ Swimbladder $\cdot$ Decompression $\cdot$ Exophthalmia

\section{INTRODUCTION}

For deep-dwelling physoclists, the rapid decompression accompanying fishery capture can cause severe barotrauma, including overexpansion of the swimbladder, crushing and bruising of internal organs, esophageal eversion, exophthalmia, and embolism in the vasculature (Feathers \& Knable 1983, Rummer \& Bennett 2005, Jarvis 2007). Studies examining the effects of capture-induced barotrauma on release behavior and survival of species of Sebastes (Pacific rockfish) show some potential for short-term (Parker et al. 2006, Hannah \& Matteson 2007, Hannah et al. 2008) and even long-term (Jarvis 2007) survival; however, only a few studies have examined the long-term effects of barotrauma on mortality, morbidity, or behavior (Gotshall 1964, Parker et al. 2006, Jarvis 2007, Brill et al. 2008). A better understanding of these effects is critical to the conservation of Pacific rockfish species, because non-retention of captured fish has become a major component of management regulations enacted to rebuild several overfished rockfish species (Pacific Fishery Management Council 2006). To evaluate the potential long-term health effects from capture-related barotrauma, a description of the most common injuries and an understanding of how these injuries are caused by rapid decompression are needed. Both have been described for some physoclists, such as red snapper 
Lutjanus campechanus (Rummer \& Bennett 2005). The external signs of barotrauma have been described for 9 species of Pacific rockfish sampled from nearshore waters off Oregon (Hannah \& Matteson 2007, Hannah et al. 2008) and for quillback rockfish $S$. maliger sampled off British Columbia (Berry 2001). Barotraumarelated internal injuries have also been described for 13 Pacific rockfish species commonly found off southern California (Jarvis 2007). Here, we present data on barotrauma-related internal injuries for 4 species of Pacific rockfish commonly captured in nearshore waters off Washington, Oregon, and northern California. We also present data and observations from airinjection experiments with black $S$. melanops and quillback $S$. maliger rockfish carcasses to describe the physical effects of overexpansion of the swimbladder. Finally, we integrate these data with other published information on the external signs of barotrauma for several rockfish species and propose a physical model that describes how rapid decompression generates the external and internal signs of barotrauma commonly seen in Pacific rockfishes.

\section{MATERIALS AND METHODS}

Internal and external signs of barotrauma. To investigate the internal and external signs of captureinduced barotrauma, we collected specimens of 4 species of rockfish including black Sebastes melanops, canary $S$. pinniger, quillback $S$. maliger, and yelloweye $S$. ruberrimus rockfish. All fish were collected with recreational hook and line gear during trips on commercial passenger fishing vessels (charter boats) operating out of Newport and Depoe Bay, Oregon, in

Table 1. Indicators used to define external signs of barotrauma in Pacific rockfish Sebastes spp.

\begin{tabular}{|c|c|}
\hline Symptom & Indicators \\
\hline Tight abdomen & $\begin{array}{l}\text { Abdomen swollen, tight to the } \\
\text { touch }\end{array}$ \\
\hline Bulging membrane & $\begin{array}{l}\text { Outward bulge in the branchio- } \\
\text { stegal membrane }\end{array}$ \\
\hline Membrane emphysema & $\begin{array}{l}\text { Air spaces or bubbles visible } \\
\text { within the branchiostegal } \\
\text { membrane }\end{array}$ \\
\hline Exophthalmia (popeye) & $\begin{array}{l}\text { Eye protruding outward from } \\
\text { orbit }\end{array}$ \\
\hline $\begin{array}{l}\text { Ocular emphysema } \\
\text { (gas in the eye) }\end{array}$ & $\begin{array}{l}\text { Gas present within the eye or } \\
\text { connective tissue surrounding } \\
\text { the eye }\end{array}$ \\
\hline Esophageal eversion & $\begin{array}{l}\text { Eversion of esophageal tissue at } \\
\text { least } 1 \mathrm{~cm} \text { into the buccal cavity }\end{array}$ \\
\hline
\end{tabular}

the summer of 2006. Each rockfish was identified to species and measured (fork length, $\mathrm{cm}$ ). Bottom depth at the capture site was recorded. The external signs of barotrauma exhibited by each fish were recorded using standardized criteria (Table 1) following Hannah \& Matteson (2007). Rockfish carcasses were individually tagged and placed in a cooler or in individual plastic bags for later dissection.

Rockfish carcasses were dissected using a longitudinal incision from the anus to just below the pericardium. Obvious internal injuries were recorded, including the condition of the liver and swimbladder; however, notes on the condition of the rete mirable were not taken. Organ displacement and the presence of blood in the abdominal cavity or in the pericardium were also evaluated. Liver condition was judged on color as well as evidence of bleeding or tearing. We used 4 classifications for the liver: (1) normal - usually white, cream, or yellow; (2) minor hemorrhage-some pink or red blotches; (3) moderate hemorrhagemostly pink; and (4) severe hemorrhage - mostly red, torn, or bloody.

Swimbladders were scored as either fully intact, partially ruptured (ruptured tunica externa), or fully ruptured, as indicated by a visible tear in both layers or by the swimbladder holding no gas or collapsing under light finger pressure. Organ displacement was scored as none, some, or severe. We defined 'some' organ displacement as the liver partially within the pharynx, but the intestines still within the abdominal cavity. Severe organ displacement was defined as intestines stretched along the abdominal cavity and most organs displaced forward into the pharynx and not visible upon incision of the abdomen.

Air injection experiments. To investigate how expanding swimbladder gas generates the internal and external signs of barotrauma in rockfish, we conducted a brief set of experiments on carcasses of black and quillback rockfish. For these experiments we used fish that had showed minimal or no signs of barotrauma at capture (no esophageal eversion, exophthalmia, or bulges or gas observed at the branchiostegal membrane) and that had been held in seawater tanks at ambient surface pressure for several months. Each fish was euthanized with an overdose of MS-222 (300 ppm, Argent Laboratories). Several specimens were also bled via the caudal vein to minimize the likelihood of blood becoming supersaturated from increased pressure in the swimbladder and transported through the body by residual heart contractions. We then injected air directly into the swimbladder using a hypodermic needle inserted through the side of the body. We used 2 methods to inject air into the swimbladder, either compressed air or a $60 \mathrm{~cm}^{3}$ syringe with a 3 -way valve that could be closed 
to maintain pressure in the swimbladder as the syringe was re-filled. As we injected air directly into the swimbladder, we noted changes in the appearance of the rockfish carcass as a result of swimbladder overexpansion. All carcasses were then dissected to examine the internal effects of swimbladder gas expansion and to verify that the injection needle had effectively pierced the swimbladder. These dissections were more extensive. In addition to examining the areas visible from the abdominal cavity, we examined the postcranial musculature, the heart, kidneys, head kidney, and the areas surrounding these organs, as well as the eyes and portions of the skull.

\section{RESULTS}

\section{Injuries in recently captured rockfish}

The rockfish carcasses we examined shortly after fishery capture showed evidence of a wide array of internal injuries from barotrauma (Table 2). Severe injuries to the liver were seen mostly in yelloweye rockfish Sebastes ruberrimus, most of which were captured much deeper than the other 3 species (Table 2). However, most fish we examined had some level of injury to the liver, as shown by pink or red blotches indicative of hemorrhage. The other types of injuries seen included partially or completely ruptured swimbladders, severe organ displacement, and blood in the pericardium or abdominal cavity. Organ displacement, sometimes severe, was seen in most of the black $S$. melanops, canary $S$. pinniger, and yelloweye $S$. ruberrimus rockfish we examined. Swimbladder rupture was highly variable and was not seen in all fish with external signs of barotrauma. For example, all of the canary, quillback, and yelloweye rockfish sampled showed evidence of gas under the branchiostegal membrane, but 43,57 , and $100 \%$ of the yelloweye, canary, and quillback rockfish, respectively, showed no clear evidence of swimbladder rupture when examined from the ventral side of the swimbladder during dissection.

The differences (between species) in the internal injuries observed showed some correspondence with the external signs of barotrauma observed. Black, canary, and yelloweye rockfish showed moderate fre- quency of swimbladder rupture and organ displacement, associated with a high frequency of esophageal eversion (Table 2). In contrast, quillback rockfish did not show any esophageal eversion and showed no evidence of swimbladder rupture or organ displacement, suggesting that the physical process of swimbladder gas expansion may proceed somewhat similarly in black, canary, and yelloweye rockfish, but differently in quillback rockfish (Table 2).

\section{Air injection experiments}

Injection of air directly into the swimbladders of rockfish carcasses (Table 3) showed that artificially increasing the volume of gas in the swimbladder readily produced all of the external signs of barotrauma commonly seen in rockfish captured in the wild (Table 2). With the exception of corneal emphysemas, the development of the signs also occurred virtually immediately, while the air was injected, demonstrating 
Table 3. Sebastes spp. External signs of barotrauma observed following the manual injection of air through the lateral body wall directly into the swimbladder of black $S$. melanops and quillback $S$. maliger rockfish carcasses using a $60 \mathrm{~cm}^{3}$ syringe or compressed air

\begin{tabular}{|c|c|c|c|c|c|c|c|}
\hline Specimen & $\begin{array}{c}\text { Volume } \\
\text { injected }\left(\mathrm{cm}^{3}\right)\end{array}$ & $\begin{array}{c}\text { Tight } \\
\text { abdomen }\end{array}$ & $\begin{array}{l}\text { Bulging } \\
\text { membrane }\end{array}$ & $\begin{array}{l}\text { Membrane } \\
\text { emphysema }\end{array}$ & Exophthalmia & $\begin{array}{c}\text { Ocular } \\
\text { emphysema }\end{array}$ & $\begin{array}{c}\text { Esophageal } \\
\text { eversion }\end{array}$ \\
\hline \multicolumn{8}{|l|}{$60 \mathrm{~cm}^{3}$ syringe } \\
\hline Black rockfish & 600 & $\mathrm{X}$ & $\mathrm{X}$ & $\mathrm{X}$ & & & $\mathrm{X}$ \\
\hline Black rockfish & 500 & $\mathrm{X}$ & $\mathrm{X}$ & $\mathrm{X}$ & $\mathrm{X}$ & $\mathrm{X}$ & \\
\hline Black rockfish $^{\mathrm{a}}$ & 1140 & $\mathrm{X}$ & $\mathrm{X}$ & $\mathrm{X}$ & $\mathrm{X}$ & $\mathrm{X}$ & \\
\hline Quillback rockfish & 1000 & $\mathrm{X}$ & $\mathrm{X}$ & $\mathrm{X}$ & $\mathrm{X}$ & $\mathrm{X}$ & \\
\hline Quillback rockfish & 1000 & $\mathrm{X}$ & & $\mathrm{X}$ & $\mathrm{X}$ & $\mathrm{X}$ & \\
\hline \multicolumn{8}{|l|}{ Compressed air } \\
\hline Black rockfish & & $\mathrm{X}$ & $\mathrm{X}$ & $\mathrm{X}$ & $\mathrm{X}$ & & \\
\hline Black rockfish & & $\mathrm{X}$ & $\mathrm{X}$ & $\mathrm{X}$ & $\mathrm{X}$ & $\mathrm{X}$ & $\mathrm{X}$ \\
\hline
\end{tabular}

that the physical expansion of swimbladder gas can generate the gross external signs of barotrauma frequently observed in wild-captured rockfish.

We also observed slow leakage of gas from a wide variety of locations on the skin of rockfish carcasses while air was injected into the swimbladders, making it impossible to relate the volumes of air injected precisely to the development of specific external signs of barotrauma. However, a typical progression of signs was observed in the carcasses injected by syringe. Following the injection of about 100 to $300 \mathrm{~cm}^{3}$ of air, bulging of the branchiostegal membrane and gas bubbles externally visible through the branchiostegal membrane were observed. Exophthalmia, with or without esophageal eversion, developed after approximately 225 to $300 \mathrm{~cm}^{3}$ of air had been injected into the swimbladders of black rockfish carcasses and after about $700 \mathrm{~cm}^{3}$ of air had been injected into the swimbladders of quillback rockfish carcasses. As exophthalmia persisted, gas was observed to invade the fascia around the eye, and then to enter the corneal layers beginning at the margins, creating corneal emphysemas. We have also observed gas invading the corneal layers from the margins of the eye in freshly captured rockfish with exophthalmia. As in the wild-caught quillback rockfish (Table 2), no esophageal eversion was noted in quillback rockfish carcasses as a result of manual swimbladder over-inflation. However, we observed air escaping from the quillback rockfish carcasses through ruptures in the branchiostegal membrane. This mechanism has been suggested by Hannah et al. (2008) as a possible explanation for the fact that quillback rockfish with barotrauma are very successful at re-submerging when released at the surface, an effect also associated with a low frequency of esophageal eversion.

Dissections of the carcasses of black and quillback rockfish following air injection to the swimbladder showed a typical pathway for escaped swimbladder gas. We noted numerous gas bubbles infusing the fascia within the postcranial musculature. Frequently, this evidence of injected swimbladder gas traveling in an anterio-dorsal direction was not accompanied by any clear evidence of ruptures in the swimbladder membranes. Gas was also found medially to the eyeball, between the globe and surrounding orbital bones. To reach this location, gas appeared to travel anteriorly along the ventral surface of the skull and into the orbit. Gas bubbles were also noted in the tissues of the kidney, head kidney, heart, pericardium, and dorsal aorta.

\section{DISCUSSION}

Considered together, these data provide new insights into the development of the common external signs of barotrauma in black, quillback and perhaps other Sebastes species (Pacific rockfish) that develop similar external signs. The data on internal and external injuries (Table 2), in combination with the results of the air injection experiments (Table 3), show that at least in some rockfish species, expanding gas escapes from the swimbladder without leaving a visibly obvious rupture (Table 2). The escape of swimbladder gas in the absence of visible rupture suggests that swimbladder expansion may lead to increased permeability. The air injection experiments with black rockfish $S$. melanops further suggest that in species that frequently develop esophageal eversion, escaping swimbladder gas tends to travel anterio-dorsally, infusing the tissues in and around the head kidney, heart, and postcranial musculature. Gas collecting in these locations likely contributes to the bulging of the branchiostegal membrane and associated gas bubbles that can frequently be observed through the branchiostegal membrane in wild-captured rockfish (Table 2 and see additional data in Berry 2001, Hannah \& Matteson 
2007, Jarvis 2007, Hannah et al. 2008). As gas volume increases in these areas, it can cause a 'rolling out' of the esophageal tissue, beginning just posterior to where it is anchored at the pharyngeal teeth. Further anterior gas travel, indicated by air bubbles observed in this experiment in the orbit, medial to the eyeball, is the likely cause of exophthalmia. After traveling distally through the ocular fascia, gas causes corneal emphysemas, generally observed as 'gas bubbles in the eye'. For quillback rockfish $S$. maliger, the data on external and internal injuries and the injection experiments suggest that escaping swimbladder gas also frequently travels anteriorly and can create similar eye effects, but generally does not collect in sufficient quantities in the area dorsal to the esophagus and posterior to the pharyngeal teeth to cause esophageal eversion, probably because it typically escapes slowly through ruptures in the branchiostegal membrane. This is supported by the low frequency of esophageal eversion reported in captured quillback rockfish (Hannah \& Matteson 2007, Hannah et al. 2008). Slow escape of swimbladder gas through ruptures in the branchiostegal membrane may also explain the finding by Berry (2001) that decreasing the rate of ascent of quillback rockfish during capture reduces the frequency of exophthalmia.

The data presented here suggest that the gross external signs of barotrauma in Pacific rockfish, although variable between species and individuals, primarily develop as a result of expanding swimbladder gases following a path of least resistance within the body of a rockfish and not from exsolution of gas from bodily fluids. For quillback and black rockfish, this path is typified by swimbladder gas moving in an anterio-dorsal direction, and either escaping through the branchiostegal membrane or accumulating in various areas that yield to gas expansion, or both. This pattern of gas expansion is also supported by magnetic resonance imaging (MRI) scans of rockfish with barotrauma (Rogers et al. 2008) that show pockets of gas anterior to the swimbladder and within the orbits, medial to the eyeball. This pattern differs from that seen in some other physoclists. For example, in red snapper Lutjanus campechanus, swimbladder expansion proceeds caudally at first, then cranially as swimbladder gas expands further (Rummer \& Bennett 2005). As might be expected, one of the most frequent barotrauma-related injuries recorded for red snapper by Rummer \& Bennett (2005) was cloacal prolapse. This sign was not noted in this study or by Hannah \& Matteson (2007) or Hannah et al. (2008), and was generally observed at levels of $<25 \%$ for the southern rockfish species studied by Jarvis (2007).

If our proposed physical model for the typical travel of swimbladder gas in these rockfish species is correct, it may be applicable to many rockfish species that show similar external signs of barotrauma. Of the 9 rockfish species considered by Hannah \& Matteson (2007) and Hannah et al. (2008), yelloweye Sebastes ruberrimus, silvergrey $S$. brevispinis, blue $S$. mystinus, tiger $S$. nigrocinctus, and widow $S$. entomelas rockfish show a high frequency of esophageal eversion that may be generated in a manner similar to what we observed here with air-injected black rockfish carcasses. Conversely, yellowtail S. flavidus rockfish showed a low frequency of esophageal eversion and may follow the model of quillback rockfish, in which gas escapes through ruptures in the branchiostegal membrane. This is supported by the observations of Pearcy (1992) of gas bubbles emanating from under the operculum of yellowtail rockfish during ascent. Of the 17 rockfish species reported on by Jarvis (2007), most showed a high frequency of esophageal eversion. With the possible exception of olive rockfish $S$. serranoides, none of the species Jarvis (2007) worked with showed a consistently low frequency of esophageal eversion at capture depths $>40 \mathrm{~m}$, as has been shown for quillback and yellowtail rockfish (Berry 2001, Hannah \& Matteson 2007, Hannah et al. 2008). Although the physical process by which the signs of barotrauma develop (and perhaps even some of the common internal injuries) may be similar between many rockfish species, studies of post-release behavior and survival suggest that survival after barotrauma varies widely between species (Hannah \& Matteson 2007, Jarvis 2007).

Knowledge of the kinds of internal injuries and the typical paths of escaping swimbladder gas associated with capture-related barotrauma is important because it can help identify potential causes of capture-related mortality in released fish, and the most likely longterm health and behavioral deficits resulting from fishery capture. This raises an interesting question: Why has the physical process of swimbladder gas expansion in Pacific rockfish received so little study? The reason may be that, although Pacific rockfish have been exploited in fisheries for many years, the conservation strategy to require the release of captured fish is a recent phenomenon (Pacific Fishery Management Council 2003) and has thus only recently prompted new interest in the health of released fish. Earlier studies of barotrauma in Pacific rockfish were directed either at estimating survival (Gotshall 1964) or on understanding normal swimbladder function in relation to behavioral ecology (McElderry 1979).

The internal injuries recorded here for 4 species of rockfish and our proposed model for typical swimbladder gas expansion suggest several areas in which capture-related barotrauma may cause mortality or long-term health problems. Potential causes for mor- 
tality include exsanguination from bleeding into the abdominal cavity, as noted by Parker et al. (2006) for black rockfish (Table 2), and vascular gas embolism interfering with cardiovascular function. The presence of gas in the aorta and heart of rockfish carcasses following injection of air into the swimbladder suggests that vascular gas embolism can occur mechanically in rockfish from swimbladder gas moving through tissues and not just from exsolution of dissolved blood gases. Longer term health deficits could arise from damage to the liver and other internal organs as a result of moderate or severe organ displacement (Table 2) or organ torsion as observed by Jarvis (2007). Damage to the kidney, head kidney, or heart as a result of anterior travel of swimbladder gas is also likely. Long-term damage to the swimbladder from rupture is also possible; however, the swimbladders of black rockfish and some other physoclists have shown an excellent ability to heal following rupture (Burns \& Restrepo 2002, Nichol \& Chilton 2006, Parker et al. 2006). Exophthalmia could also lead to vision deficits via the stretching or parting of the optic nerve (Rogers et al. 2008) and corneal emphysemas could lead to long-term loss of visual acuity from corneal damage. This is supported by the finding of Berry (2001) of a high incidence of permanent eye damage in quillback rockfish that survived capture-related barotrauma.

Acknowledgements. Tim Miller-Morgan assisted with interpretation of dissections. The charter fishing vessels, 'Misty', operating out of Newport, Oregon, and 'Tacklebuster', 'Samson', and 'Endeavor' operating out of Depoe Bay, Oregon, assisted with the fish collection for the present study. Troy V. Buell, Alena Pribyl, Matthew Blume, and Keith Matteson also assisted with this research. The Research Experiences for Undergraduates program at Oregon State University (National Science Foundation Award OCE-0353083) provided funding for A.N.P.

\section{LITERATURE CITED}

Berry MD (2001) Area 12 (inside) rockfish selective fishery study. Project No. FS00-05, Science Council of British Columbia

Brill R, Magel C, Davis MW, Hannah RW, Rankin PS (2008) Effects of events accompanying capture (rapid decompression and exposure to bright light) on visual function in

Editorial responsibility: Victor Benno Meyer-Rochow, Bremen, Germany black rockfish (Sebastes melanops) and Pacific halibut (Hippoglossus stenolepis). Fish Bull (Wash DC) (in press)

Burns KM, Restrepo V (2002) Survival of reef fish after rapid depressurization: field and laboratory studies. Am Fish Soc Symp 30:148-151

Feathers MG, Knable AE (1983) Effects of depressurization upon largemouth bass. N Am J Fish Manag 3:86-90

Gotshall DW (1964) Increasing tagged rockfish (genus Sebastodes) survival by deflating the swim bladder. Calif Fish Game 50:253-260

> Hannah RW, Matteson KM (2007) Behavior of nine species of Pacific rockfish after hook-and-line capture, recompression and release. Trans Am Fish Soc 136:24-33

> Hannah RW, Parker SJ, Matteson KM (2008) Escaping the surface: the effect of depth of capture on submergence success of surface-released Pacific rockfish. N Am J Fish Manag 28:694-700

Jarvis ET (2007) The effects of barotrauma on the catch-andrelease survival of southern California nearshore and shelf rockfishes (Scorpaenidae, Sebastes spp.). MSc thesis, California State University, Long Beach, CA

McElderry HI (1979) A comparative study of the movement habits and their relationship to buoyancy compensation in two species of shallow reef rockfish (Pices, Scorpaenidae). MSc thesis, University of Victoria, Victoria, BC

Nichol DG, Chilton EA (2006) Recuperation and behavior of Pacific cod after barotrauma. ICES J Mar Sci 63:83-94

Pacific Fishery Management Council (2003) Final environmental impact statement for the proposed groundfish acceptable biological catch and optimum yield specifications and management measures: 2003 Pacific Coast groundfish fishery. Pacific Fishery Management Council, Portland, OR

Pacific Fishery Management Council (2006) Proposed acceptable biological catch and optimum yield specifications and management measures for the 2007-2008 Pacific coast groundfish fishery, and Amendment 16-4: rebuilding plans for seven depleted Pacific coast groundfish species: final environmental impact statement including regulatory impact review and initial regulatory flexibility analysis. Pacific Fishery Management Council, Portland, OR

Parker SJ, McElderry HI, Rankin PS, Hannah RW (2006) Buoyancy regulation and barotrauma in two species of nearshore rockfish. Trans Am Fish Soc 135:1213-1223

Pearcy WG (1992) Movements of acoustically-tagged yellowtail rockfish Sebastes flavidus on Heceta Bank, Oregon. Fish Bull (Wash DC) 90:726-735

> Rogers BL, Lowe CG, Fernández-Juricic E, Frank LR (2008) Utilizing magnetic resonance imaging (MRI) to assess the effects of angling-induced barotrauma on rockfish (Sebastes). Can J Fish Aquat Sci 65:1245-1249

Rummer JL, Bennett WA (2005) Physiological effects of swim bladder overexpansion and catastrophic decompression on red snapper. Trans Am Fish Soc 134:1457-1470

Submitted: May 26, 2008; Accepted: July 29, 2008 Proofs received from author(s): September 4, 2008 